\title{
Lotus japonicus Gene Ljsbp Is Highly Conserved Among Plants and Animals and Encodes a Homologue to the Mammalian Selenium-Binding Proteins
}

\author{
Emmanouil Flemetakis, ${ }^{1}$ Adamantia Agalou, ${ }^{2}$ Nektarios Kavroulakis, ${ }^{1}$ Maria Dimou, ${ }^{1}$ \\ Anna Martsikovskaya, ${ }^{1}$ Andrian Slater, ${ }^{3}$ Herman P. Spaink, ${ }^{2}$ Andreas Roussis, ${ }^{2}$ \\ and Panagiotis Katinakis ${ }^{1}$ \\ ${ }^{1}$ Agricultural University of Athens, Department of Agricultural Biotechnology, lera Odos 75, 11855 Athens, Greece; \\ ${ }^{2}$ Institute of Molecular Plant Sciences, Leiden University, Clusius Laboratory, Wassenaarseweg 64, 2333 AL Leiden, \\ The Netherlands; ${ }^{3}$ Norman Borlaug Institute for Plant Science Research, De Montfort University, Scraptoft Leicester, \\ Leicestershire, LE 795U U.K.
}

Submitted 21 September 2001. Accepted 4 December 2001.

We have isolated and characterized a Lotus japonicus gene (Ljsbp) encoding a putative polypeptide with striking homology to the mammalian 56-kDa selenium-binding protein (SBP). cDNA clones homologous to $L j S B P$ were also isolated from soybean, Medicago sativa, and Arabidopsis thaliana. Comparative expression studies in L. japonicus and $A$. thaliana showed that $s b p$ transcripts are present in various tissues and at different levels. Especially in L. japonicus nodules and seedpods and $A$. thaliana siliques, $s b p$ expression appears to be developmentally up-regulated. sbp Gene transcripts were localized by in situ hybridization in the infected cells and vascular bundles of young nodules, while in mature nodules, low levels of expression were only detected in the parenchymatous cells. Expression of $s b p$ transcripts in young seedpods and siliques was clearly visible in vascular tissues and embryos, while in embryos, low levels of expression were detected in the root epidermis and the vascular bundles. Polyclonal antibodies raised against a truncated $L$ jSBP recombinant protein recognized a polypeptide of about $60 \mathrm{kDa}$ in nodule extracts. Immunohistochemical experiments showed that accumulation of $L j S B P$ occurred in root hairs, in the root epidermis above the nodule primordium, in the phloem of the vasculature, and abundantly in the infected cells of young nodules. Irrespective of the presence of rhizobia, expression of SBP was also observed in root tips, where it was confined in the root epidermis and protophloem cells. We hypothesize that $\mathrm{LjSBP}$ may have more than one physiological role and can be implicated in controlling the oxidation/reduction status of target proteins, in vesicular Golgi transport, or both.

The interaction of the soil bacteria in the genera Rhizobium, Mesorhizobium, Azorhizobium, Sinorhizobium, and Bradyrhizobium with the root system of leguminous plants leads to the formation of a specialized plant organ, the root nodule. During the course of nodule initiation and development, a

Corresponding author: P. Katinakis; E-mail: bmbi2kap@ auadec.aua.gr

Nucleotide sequence data are available in the EMBL database under accession numbers AJ401226 (Ljsbp), AJ401227 ( $L j \mathrm{SBP}$ ), AJ401228 (MsSBP), AJ401229 (AtSBP), and AJ401230 (GmSBP). number of plant genes, referred to as nodulin genes, are induced (Mylona et al. 1995). Recently, however, the number of nodulin genes whose expression is also found in tissues other than nodules has increased considerably. For example, one of the nodulin genes expressed at very early stages of nodule initiation (ENOD40) is also expressed in roots, stems, and embryos (Fang and Hirsch 1998; Flemetakis et al. 2000; Papadopoulou et al. 1996). Furthermore, several of the nodulin genes, including NOD35 (Takane et al. 1997) and phosphoenolpyruvate carboxylase (Hata et al. 1998), are highly expressed in symbiotic tissues but at much lower levels than in nonsymbiotic tissues. Homologues of several nodulin genes, including leghemoglobin, NOD93, NOD35, and ENOD40, have been found in legume and nonlegume plants (Kouchi et al. 1999; Marchfelder et al. 1997; Matvienko et al. 1995; Reddy et al. 1998; Trevaskis et al. 1997). A number of structural and functional homologues of nodulin genes have also been found in bacteria and animals; for instance, a homologue for NOD26 encoding a protein of the peribacteroid membrane displayed a high amino acid similarity with a protein present in rats and bovine lens fiber cell membrane (Sandal and Marcker 1988; Shiels et al. 1988) and Escherichia coli GlpF glycerol facilitator (Dean et al. 1999). The predicted amino acid sequence of soybean nodulin $G m$ N56 showed significant homology to the bacterial isopropylmalate synthase and homocitrate synthase (Kouchi and Hata 1995).

Only a few nodulin genes have been functionally analyzed with reverse or forward genetics (Charon et al. 1999; Schauser et al. 1999). The function of the majority of the reported nodulin genes, with the exception of a limited number that are involved in carbon (Kavroulakis et al. 2000) or nitrogen (Mylona et al. 1995) metabolism or other enzymes catalyzing certain enzymatic reactions such as protein phosphatase 2C (Kapranov et al. 1999), has been proposed based on their expression patterns and their correlation with different symbiotic events, such as preinfection, infection, and nodule meristematic initiation or nodule structure formation (Cook et al. 1995; Crespi et al. 1994; Scheres et al. 1990).

In this report, we describe the isolation and characterization of a novel Lotus japonicus gene that codes for a homologue of a selenium-binding protein (SBP) and whose predicted amino acid sequence is conserved in both plant and animals. Since $L$. japonicus is one of the two model legumes used to study the 

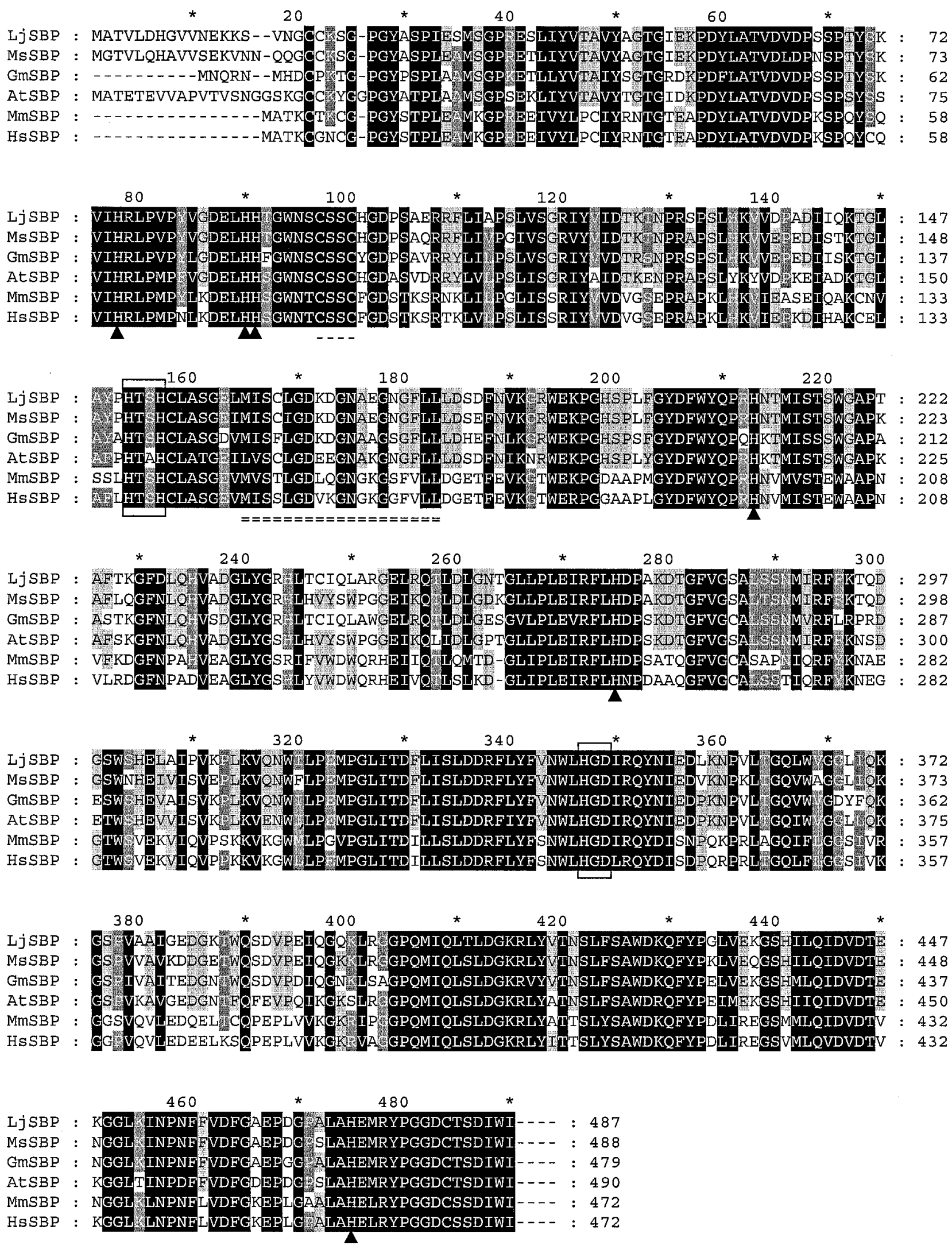

Fig. 1. Comparison of the deduced amino acid sequences of selenium-binding protein (SBP) from various organisms. Organism symbols and GenBank database accession numbers are as follows. LjSBP, Lotus japonicus (this work); MsSBP, Medicago sativa (this work); AtSBP, Arabidopsis thaliana (O23264); HsSBP, Homo sapiens (XP-001336); and MmSBP, Mus musculus (P17563) (Bansal et al. 1990). Black-shaded boxes represent conserved amino acids, while gaps in the alignment are represented by dashes. The putative CSSC sequence motif is underlined and the putative metal-binding sites $\mathrm{HxD}$ and $\mathrm{HxxH}$ are boxed. Additional conserved $\mathrm{H}$ residues are marked with arrowheads $(\boldsymbol{\Delta})$. The protein domain showing very high similarity with the Petroselenium crispum anionic peroxidase (Kawalleck et al. 1995) is double underlined. 
function of genes involved in symbiosis and since Arabidopsis thaliana is widely used in the identification of the function of plant genes, we set out to characterize the structure and expression of the $s b p$ genes in these plants as the first step toward elucidating their function.

\section{RESULTS}

\section{Identification and characterization}

of plant cDNA clones coding for proteins

with high similarity to the mammalian SBPs.

In a previous study, several cDNA clones were isolated by the differential screening of cDNA libraries prepared from mature and young soybean nodules (Gloudemans 1988). Northern blot analysis of one of these clones, designated GmNOD9, hybridized to a transcript of about 1,900 nucleotides that accumulated to a maximal level 13 days postinfection (dpi) with Bradyrhizobium bacteria, while in mature nodules (28 dpi), the level of accumulation was reduced. GmNOD9 transcripts were also found in roots, leaves, and seedpods of soybean (data not shown). An overlapping cDNA clone was obtained by $5^{\prime}$ rapid amplification of cDNA clone ends (RACE). The combined length of the RNA based on the two overlapping cDNA clones is 1,695 base pairs (bp), excluding the polyA tail. This RNA encodes an open reading frame (ORF) of 478 amino acids. A protein database search revealed that this putative soybean polypeptide is highly homologous to the human and mouse $56-\mathrm{kDa}$ SBP (Fig. 1). Therefore, the soybean gene was designated $G m$ SBP. Searches in GenBank expressed sequence tag (EST) databases revealed that the amino acid sequence of $G m \mathrm{SBP}$ is conserved in the translation products of ESTs from A. thaliana (ATTS2295), maize (AI770427), rice (AU030352), tomato (AI777950), watermelon (AA660150), Pinus taeda (AA739911), and Physcomitrella patens (AJ225507). The cDNA clone for the Arabidopsis EST was obtained from the Arabidopsis Biological Research Center (Ohio State University, Columbus), and its complete nucleotide sequence was determined. This cDNA clone (designated AtSBP) contains an ORF of 470 amino acids (Fig. 1).

In addition to EST sequences, a number of translated genomic sequences showed high homology to both plant and mammalian SBP proteins. These include genomic sequences of A. thaliana (O23264 and O23265), Caenorhabditis elegans (T26612), and Drosophila melanogaster (QAAF54900). No homologous sequences were identified in the translated genomic sequences of yeast.

In order to isolate the corresponding cDNA clone from $L$. japonicus, we screened a cDNA library prepared from 9- and 21-day-old nodules with the GmSBP cDNA clone as a probe.
Several positive recombinant phages were identified and sequenced. The largest cDNA clone (designated LjSBP) contains an ORF of 487 amino acid residues (Fig. 1). Several cDNA clones were also isolated from a Medicago sativa somatic embryo cDNA library using a cloned polymerase chain reaction (PCR) fragment as a probe. The PCR fragment was generated using degenerate primers and $M$. sativa genomic DNA as a template and appropriate degenerate primers. The largest cDNA clone (designated $M s S B P$ ) contains an ORF of 488 amino acid residues (Fig. 1).

Alignment of the deduced amino acid sequences derived from plant (soybean, L. japonicus, M. sativa, and A. thaliana) and mammalian (mouse and human) SBP cDNA clones showed that the identity between the predicted proteins ranged from 77 to $88 \%$ in plants and was $86 \%$ for the mammalian proteins of mouse and man (designated MmSBP and HsSBP, respectively), while the identity of the plant with mammalian genes ranged from 57 to $60 \%$. Prosite database searches revealed the presence of a conserved CSSC motif in both plant and mammalian SBP proteins (Fig. 1). Cysteine residues in such motifs are characteristic of a group of redox proteins (e.g., thioredoxins, thioredoxin reductase, and protein disulfide isomerase) that are involved in reducing disulfide bridges in target proteins (Meyer et al. 1999). The amino acid sequences of all the putative SBPs compared contained a high percentage (about 3\%) of histidine residues, some of which appear to be part of putative metal-binding motifs of the $\mathrm{HxD}$ or the $\mathrm{HxxH}$ types (Fig. 1).

Southern blot analysis was performed to determine the number of $s b p$ genes in the L. japonicus and A. thaliana genomes. The hybridizing bands indicated that in L. japonicus only one gene is present, while in A. thaliana, there are two (data not shown). This is in agreement with a report of the A. thaliana genome sequencing project (Bevan et al. 1998), in which two Atsbp genes (in head to tail arrangement, designated as Atsbp-1 and Atsbp-2) were identified (Fig. 2). The coding regions of the two A. thaliana Atsbp genes shared $86 \%$ identity. A L. japonicus genomic library was screened using the LjSBP cDNA clone as a probe, and nucleotide sequence analysis of the isolated genomic clones indicated that the Ljsbp gene contains six introns (Fig. 2).

Expression of the $s b p$ gene in various tissues of $L$. japonicus.

To gain an insight into the accumulation levels of Ljsbp gene transcripts, total RNA was isolated from different $L$. japonicus tissues (root, leaves, stems, flowers, seedpods, cotyledons, and hypocotyls) as well as from nodules at different developmental stages and a semiquantitative reverse-transcription (RT)-PCR approach was employed (Fig. 3). Accumulation of LjSBP

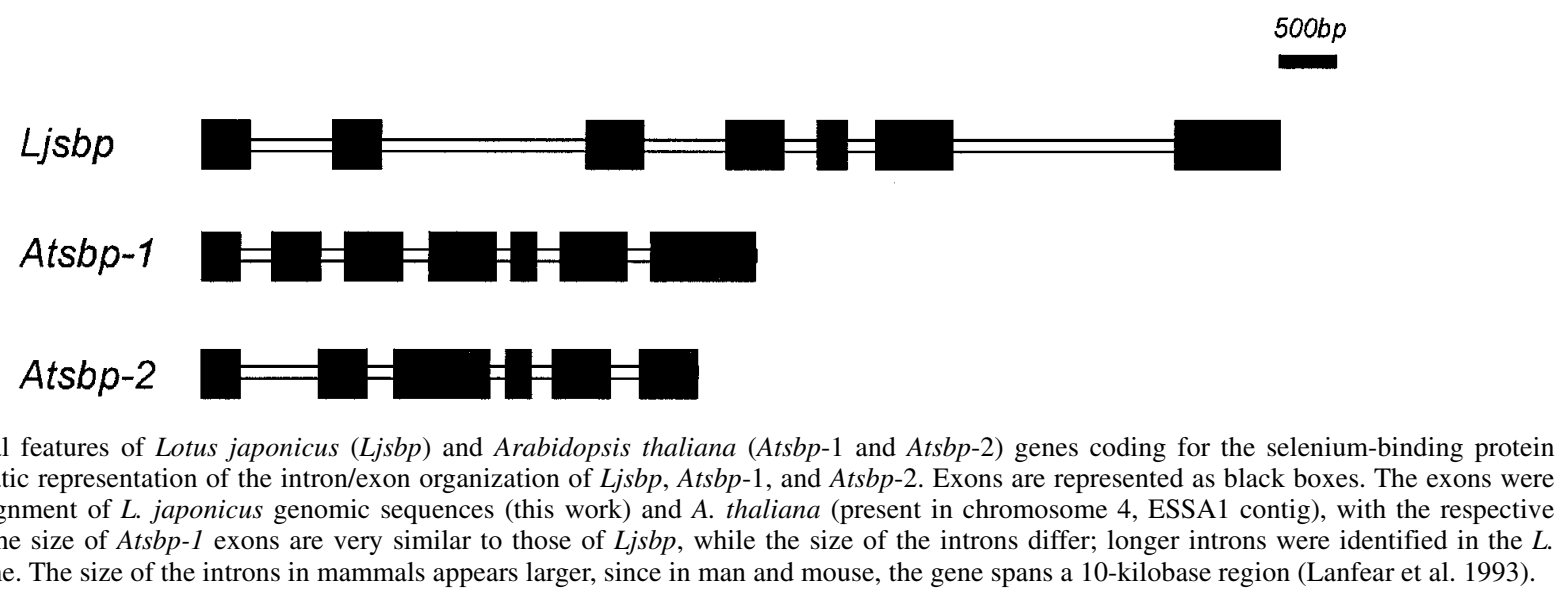

Fig. 2. Structural features of Lotus japonicus (Ljsbp) and Arabidopsis thaliana (Atsbp-1 and Atsbp-2) genes coding for the selenium-binding protein (SBP). A schematic representation of the intron/exon organization of $L j s b p$, Atsbp-1, and Atsbp-2. Exons are represented as black boxes. The exons were defined after alignment of L. japonicus genomic sequences (this work) and A. thaliana (present in chromosome 4, ESSA1 contig), with the respective cDNA clones. The size of Atsbp- 1 exons are very similar to those of $L j s b p$, while the size of the introns differ; longer introns were identified in the $L$. japonicus genome. The size of the introns in mammals appears larger, since in man and mouse, the gene spans a 10-kilobase region (Lanfear et al. 1993). 
mRNAs was high in infected roots at $1 \mathrm{dpi}$, reached a maximum level in nodules at $14 \mathrm{dpi}$, and then gradually decreased (Fig. 3B). Accumulation of Ljsbp gene transcripts in flowers was comparable to the levels found in nodules at $14 \mathrm{dpi}$ (Fig. 3A). High levels of Ljsbp gene transcripts were detected in pods, roots, young hypocotyls, and apical meristems. The abundance of transcripts was reduced in siliques during the maturation phase (data not shown). A very low level of hybridization signal was observed in stems and an even lower level in leaves (Fig. 3A).

An estimation of the accumulation levels of Atsbp gene transcripts was performed using total RNA isolated from various tissues and organs of Arabidopsis plants by northern blot analysis. The Atsbp genes were expressed at high levels in young siliques. Relatively lower levels of expression were found in roots, flowers, seedlings, and leaves, and a very low level of expression was observed in stems and rosettes (data not shown). In siliques, the transcript level decreased during seed maturation (data not shown).

\section{Localization of Ljsbp gene transcripts in nodules and seedpods.}

The spatial localization of $L j s b p$ gene transcripts during nodule development was examined using in situ hybridization. Seven-meter sections of $L$. japonicus nodules at various stages of nodule development were hybridized with digoxigeninUTP-labeled RNA probes transcribed from the LjSBP cDNA clone. Both sense and antisense transcripts were used as probes. At 14 dpi with Mesorhizobium loti, the Ljsbp gene was highly expressed in the developing vascular bundles and in the infected cells (Fig. 4A). Detectable levels of transcripts were also observed in parenchymatous cells (Fig. 4B). In a nodule at $21 \mathrm{dpi}$, Ljsbp gene transcripts were still present at high levels in vascular bundles, connecting vascular tissue, and the parenchyma (Fig. 4C), while the signal in the cells of the central tis-
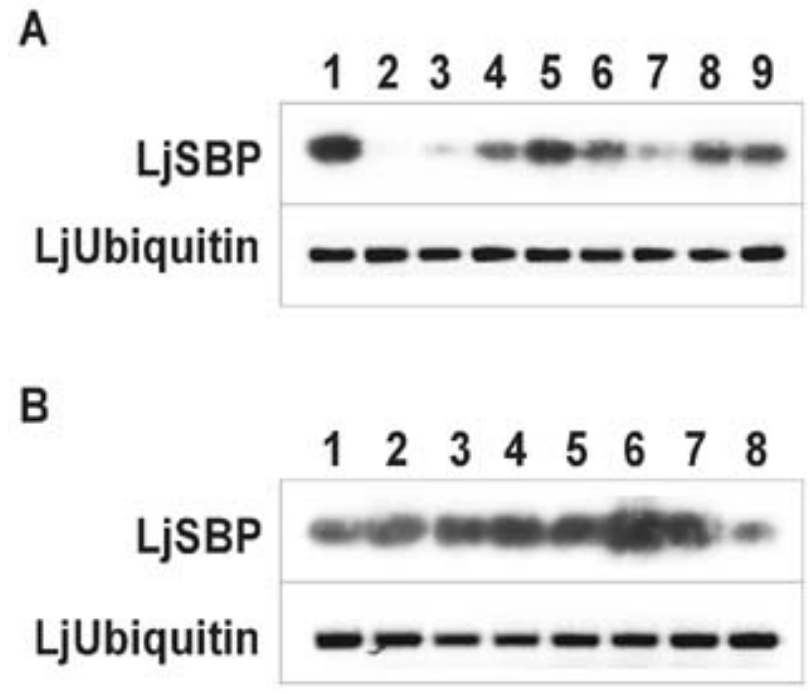

Fig. 3. Accumulation of $L j S B P$ mRNAs in Lotus japonicus nodules and nonsymbiotic tissues. Total RNA was isolated from different tissues as indicated and was subjected to reverse-transcription-polymerase chain reaction analysis using $L$. japonicus ubiquitin as an internal control. The products of the amplification reaction were analyzed on a $1.5 \%$ agarose gel, blotted on a nylon membrane, and hybridized to ${ }^{32} \mathrm{P}-\mathrm{dCTP}$-labeled insert of the LjSBP cDNA clone. A, Lanes 1 to 9, The expression levels at 14 days postinfection (dpi) in root nodules, leaves, stems, uninfected roots, flowers, green seedpods, cotyledons, apical meristems, and hypocotyls, respectively. B, Lane 1, Uninfected roots; lanes 2 to 5 , roots at 1, 3, 5, and 10 dpi with Mesorhizobium loti, respectively; and lanes 6 to 8, nodules at 14,21 , and $30 \mathrm{dpi}$, respectively. sue was lower (Fig. 4D). In nodules at $28 \mathrm{dpi}$, a low level of signal was detected only in the vascular bundles and parenchymatous cells, whereas no signal was detected in the central tissue (Fig. 4E and F). A similar pattern of expression was also observed in developing soybean nodules (data not shown).

The localization of Ljsbp and Atsbp gene transcripts was also examined in L. japonicus young seedpods as well as in $A$. thaliana siliques and embryos. In green $L$. japonicus young seedpods, accumulation of LjSBP mRNAs was detected in developing embryonic tissues at the early and late globular stages (Fig. 4H and G), the ovule and silique vascular system, the inner ovary wall, the outer integument, and the ovule epithelium (Fig. 4G and $\mathrm{H}$ ). In mature $A$. thaliana siliques, signal was found at low levels in root vascular bundles (Fig. 4J), root epidermis, and cotyledon vascular bundles (Fig. 4J and K), while high levels of AtSBP mRNA transcripts were detected in the heart stage embryo (Fig. 4I).

\section{Immunohistological localization of $L j S B P$ polypeptide in developing nodules and in roots.}

To determine whether the accumulation of SBP protein follows the spatial and temporal patterns of mRNA accumulation, immunohistological experiments were performed. A rabbit polyclonal antibody was raised against a recombinant truncated LjSBP protein and used to carry out a western blot analysis using total protein extracts from $L$. japonicus root nodules at various stages of development (Fig. 5). A single band of about $60 \mathrm{kDa}$ could be consistently detected in the extracts derived from the L. japonicus nodules. The apparent molecular masses were larger than the predicted molecular mass, since expression of a full-length $\mathrm{LjSBP}$ cDNA clone in E. coli revealed the presence of a 56-kDa protein (data not shown). These discrepancies might be due to posttranslational modifications of the SBP polypeptide. The amount of SBP greatly declined during nodule development after 14 dpi (Fig. 5).

The tissue distribution of $L j \mathrm{SBP}$ protein was examined during nodule development using the antibodies (Fig. 6). During the very early stages of the interaction with rhizobia, accumulation of $L j S B P$ was observed in the root epidermis and the emerging root hairs of the responsive zone of the root as well as in the root vasculature (Fig. 6A). At the position where the first cortical cell divisions occur, just below the growing infection thread, LjSBP was immunolocalized in a few epidermal cells but primarily in the cortical root hair containing the infection thread and in the phloem of the vascular cylinder (Fig. 6B and $\mathrm{C}$ ). In different stages of nodule primordium formation (Fig. 6D to F), this accumulation pattern remained, but additionally, very low levels of $L j S B P$ could be detected in the cells of the nodule primordium. Furthermore, the signal in the epidermis was increased, mostly at the site of the emerging primordium. In fully differentiated nodules (14 to $18 \mathrm{dpi}$ ), LjSBP was detected in high levels in the infected cells of the central tissue as well as in the vascular bundles (Fig. 6G and $\mathrm{H}$ ) and the connecting root vascular tissue (Fig. 6I). Protein could also be detected in the parenchymatous cells of the nodule (Fig. 6I). In mature nodules ( 21 to $28 \mathrm{dpi}$ ), the levels of $L j \mathrm{SBP}$ in the infected cells were significantly reduced (Fig. 6J and K). Our western blot and immunohistological analyses showed that SBP was found in nodules at $28 \mathrm{dpi}$, when the levels of SBP mRNAs were negligible. This discrepancy could be attributed to a high stability of the protein.

The immunolocalization of $L j S B P$ in the root cortex and epidermis surrounding the nodule primordium prompted us to study the accumulation of the polypeptide also in the uninfected root tissue. Our experiments showed that LjSBP was expressed in the root tips and that this pattern could be uncoupled from the presence of rhizobia, since identical results 


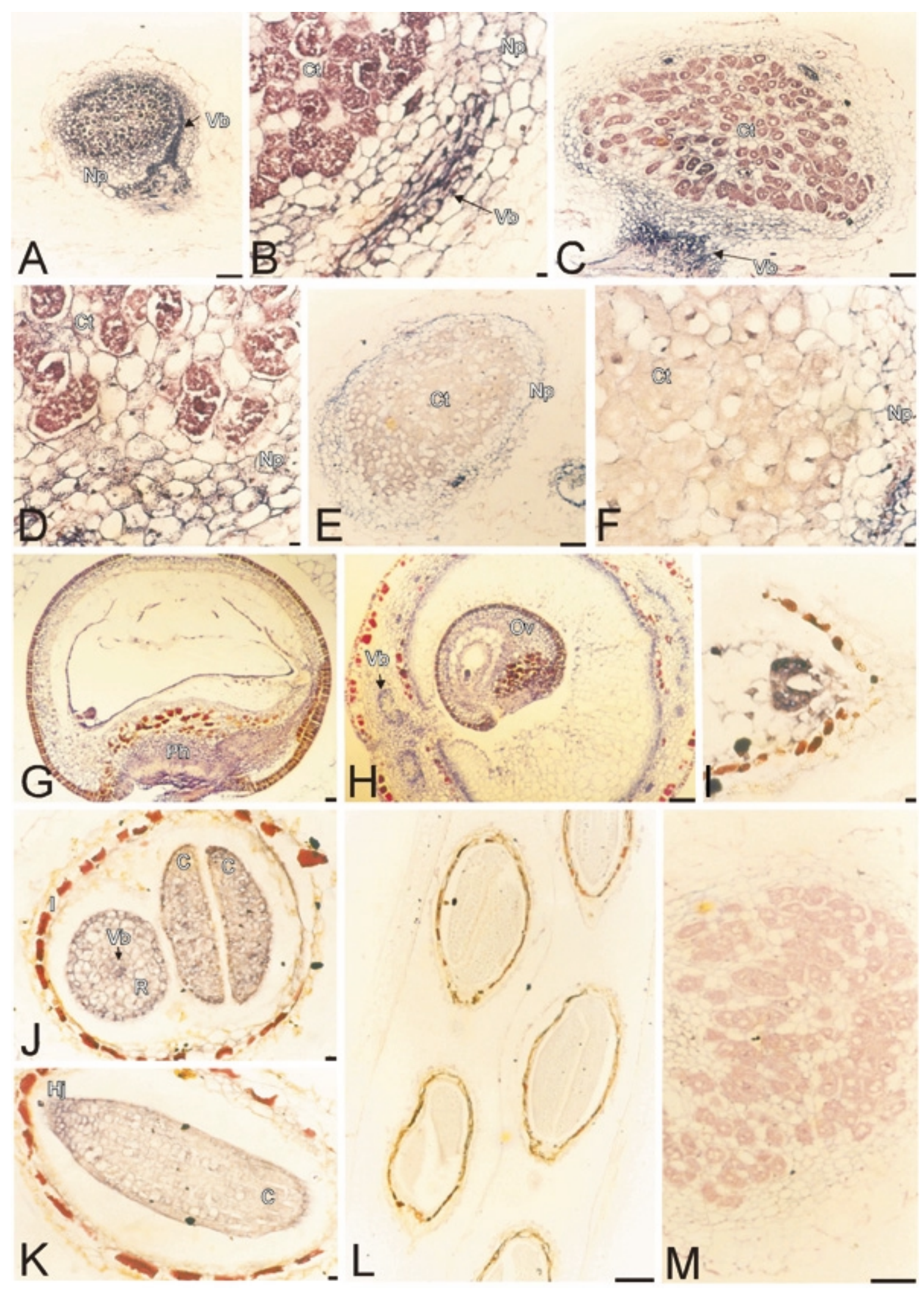

Fig. 4. In situ localization of $s b p$ gene transcripts in nodules and seedpods of Lotus japonicus and siliques of Arabidopsis thaliana. Longitudinal sections of nodules at A, B, and L, 14; $\mathbf{C}$ and $\mathbf{D}, 21 ;$ and $\mathbf{E}$ and $\mathbf{F}, 28$ days postinfection and $\mathbf{G}$, longitudinal and $\mathbf{H}$, transverse sections of $L$. japonicus seedpods were hybridized with digoxigenin-labeled antisense RNA, in vitro-transcribed from the LjSBP cDNA clone. B, D, and F, A close-up view of nodular regions from $\mathbf{A}, \mathbf{C}$, and $\mathbf{E}$, respectively. A sense probe was used in the section presented in $\mathbf{M}$. I, $\mathbf{K}$, and $\mathbf{L}$, Longitudinal and $\mathbf{J}$, transverse sections of $A$. thaliana siliques were hybridized with digoxigenin-labeled RNA, in vitro-transcribed from the AtSBP cDNA clone. A sense probe was used in section presented in $\mathbf{L}$; in all other sections, an antisense probe was used. The hybridization signal is visible as a blue-purple precipitate. A, C, E, G, $\mathbf{H , ~} \mathbf{L}$, and $\mathbf{M}$, Bars $=100 \mu \mathrm{m}$. B, D, I, J, and K, Bars $=10 \mu \mathrm{m}$. Vb, vascular bundles; Ct, central tissue; Np, nodule parenchyma; Ov, ovule; Ph, phloem; R, root; C, cotyledon; I, inner integument; and $\mathrm{Hj}$, hypocotyl junction. 
were obtained in the presence or absence of Mesorhizobium loti. Very low levels of the protein, slightly above detection levels, could be observed in the central cylinder of the root before the tip (data not shown). In longitudinal sections of root tips, high levels of $L j S B P$ were present in the epidermis and the outer cortex as well as in the vasculature (Fig. 7A to D). In order to define in which cell type of the root vasculature SBP was localized, we analyzed transverse sections of root tips. This showed that, except in the epidermis and the outer cortex, LjSBP accumulated in the protophloem cells of the root stele (Fig. 7G to I).

\section{DISCUSSION}

We have identified and characterized a gene from L. japonicus that codes for a polypeptide that is highly homologous to a mammalian SBP. Homologues of this gene called LjSBP are also found in many multicellular organisms such as $A$. thaliana, Caenorhadbitis elegans, D. melanogaster, Danio rerio, and Homo sapiens but not in Saccharomyces cereviciae. In addition, homologous sequences were also found in abundance in ESTs from different plant and animal tissues. Secondary structure predictions indicate that SBP proteins in both plants and animals are not transmembrane proteins. The size of the SBP proteins is also conserved between different species, with the amino acids identity spanning the whole length of the polypeptide. Relatively few classes of proteins are conserved to this extent, especially between plants and animals. The most highly conserved proteins include the histones, actin, ubiquitin, $\gamma$-tubulin, heat shock proteins, 14-3-3 proteins (Doolittle 1992; Radice et al. 1995), defender against apoptotic death 1 protein (Gallois et al. 1997), and eIF4E (Rodriguez et al. 1998). While the plant SBP protein sequence is not conserved to the exceptional degree of heat shock protein HS70 (human/soybean, $75 \%$ ), it is significantly more conserved than heat shock protein HSP60, $\gamma$-tubulin, apoptotic cell death 1 protein, and elF4E (identity of plant and human forms is $44,49,48$, and $52 \%$, respectively). Such a high degree of conservation of amino acid sequences among the SBP proteins identified in distantly related organisms argues for a fundamental biological role for these proteins.

Recently, Porat and colleagues (2000) reported on the functional analysis of the rat SBP56 protein and showed that it is associated with the Golgi membrane and participates in late stages of intra-Golgi protein transport. The implication of SBP56 in vesicular transport is in line with our findings that LjSBP accumulates in high levels in root hairs during infection thread formation (Fig. 6B and C) and in the infected cells of the nodule central tissue (Fig. 6G to J). Characteristic of the cytoplasm surrounding the tip of the infection thread are, among others, a well-developed, rough endoplasmic reticulum and vesicles (Kijne 1992). Formation of the walls and mem-

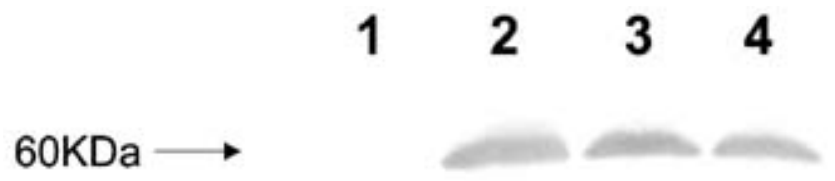

Fig. 5. Accumulation of selenium-binding protein (SBP) protein in Lotus japonicus nodules at various developmental stages. Western blot of total protein extracts from the cytoplasmic fraction of nodules at 14,21 , and 28 days postinfection (lanes 2 to 4 , respectively) was probed with SPB antibodies raised against the first $349 \mathrm{~N}$-terminal amino acids of the SBP protein. Lane 1, Total Escherichia coli extracts. Signal was visualized with alkaline-phosphatase (purple-blue color). Each lane contains $20 \mu \mathrm{g}$ of protein. branes of the infection threads and of the peribacteroid membranes involves fusion of the cytoplasmic vesicles with these membranes, and in lupin, evidence exists that these vesicles are Golgi derived (Robertson et al. 1978). Furthermore, experiments with monoclonal antibodies against the membrane glycoprotein MAC 64 have shown the association of the Golgi apparatus with the symbiosome membrane (Brewin et al. 1988), and Roth and Stacey (1989a, 1989b) have suggested, with studies in soybean nodules and Bradyrhizobium mutants, that the extensive membrane synthesis necessary for the symbiosome membrane formation is carried out both from the endoplasmic reticulum (ER) and through the Golgi-apparatus synthesis.

Comparison of the amino acid sequences deduced from plant and mammalian cDNAs coding for SBP revealed the presence of several conserved motifs in the deduced polypeptides. The conserved CSSC motif present in both plant and animal SBP proteins contains two adjacent cysteines separated by two amino acid residues; a characteristic feature of several proteins that are involved in controlling the oxidation/reduction status (redox proteins) of target proteins in vivo (Meyer et al. 1999). The redox status of SBP may also influence the conformation of the protein and consequently its binding capacity for selenium by exposing more of the selenium-binding sites. Proteins containing this sequence (CSSC) have also been found to have a strong affinity for selenium (Jamba et al. 1997; Liu and Stadtman 1997). The conservation of three histidine residues (H75, H87, and H88) near the CSSC sequence in SBP and the conserved metal-binding domains $\mathrm{HxxH}$ (H151 and H154) and $\mathrm{HxD}$ (H343) points to this direction, since they represent potential sites for selenium binding. The putative function of the SBP protein as a redox protein could be further analyzed either by antisense or overexpression approaches. However, even the function of well-known cytoplasmic redox or redoxlike proteins (e.g., thioredoxin $h$ ) in plants is still unclear (Meyer et al. 1999). Overexpression of thioredoxin $h$ leads to enhanced activity of pullulanase during germination and seedling development in barley (Cho et al. 1999). The number and distribution of the conserved amino acids motifs in combination with the amino acid sequence conservation over the whole length of the SBP polypeptides indicate that these proteins may be evolutionarily conserved because of specific structural constraints necessary for their function.

Semiquantitative RT-PCR and northern blot hybridization showed that SBP mRNA is detected in all the plant tissues examined, albeit at variable levels. For example, in nodules, seedpods, and siliques, the abundance of the messenger varied considerably depending upon the developmental stage (Fig. 2). The up regulation of $s b p$ gene transcripts in infected cells and vascular bundles in young nodules or in the vascular system and embryonic tissues of pods or siliques implies that high levels of SBP protein are required during organogenesis. Marked differences in the transcriptional regulation of SBP mRNA were also found among various tissues in mammals. In humans, elevated expression was observed in liver, lung, colon, kidney, and pancreas, whereas peripheral blood leucocytes, brain, testis, and thymus exhibited minimal transcript levels (Lanfear et al. 1993; Yang and Sytkowski 1998). It could be argued, however, that SBP proteins are mainly required at significant levels in tissues that are metabolically very active. The importance of the variation in the transcript levels at the different developmental stages of nodules and embryos has to be further analyzed. Comparison of the mRNA and protein accumulation in developing nodules shows that, in both cases, the cell types in which SBP is detected are the same. The fact that the $s b p$ transcripts are at negligible levels in nodules at $28 \mathrm{dpi}$ while the translational product is still found at detectable levels 


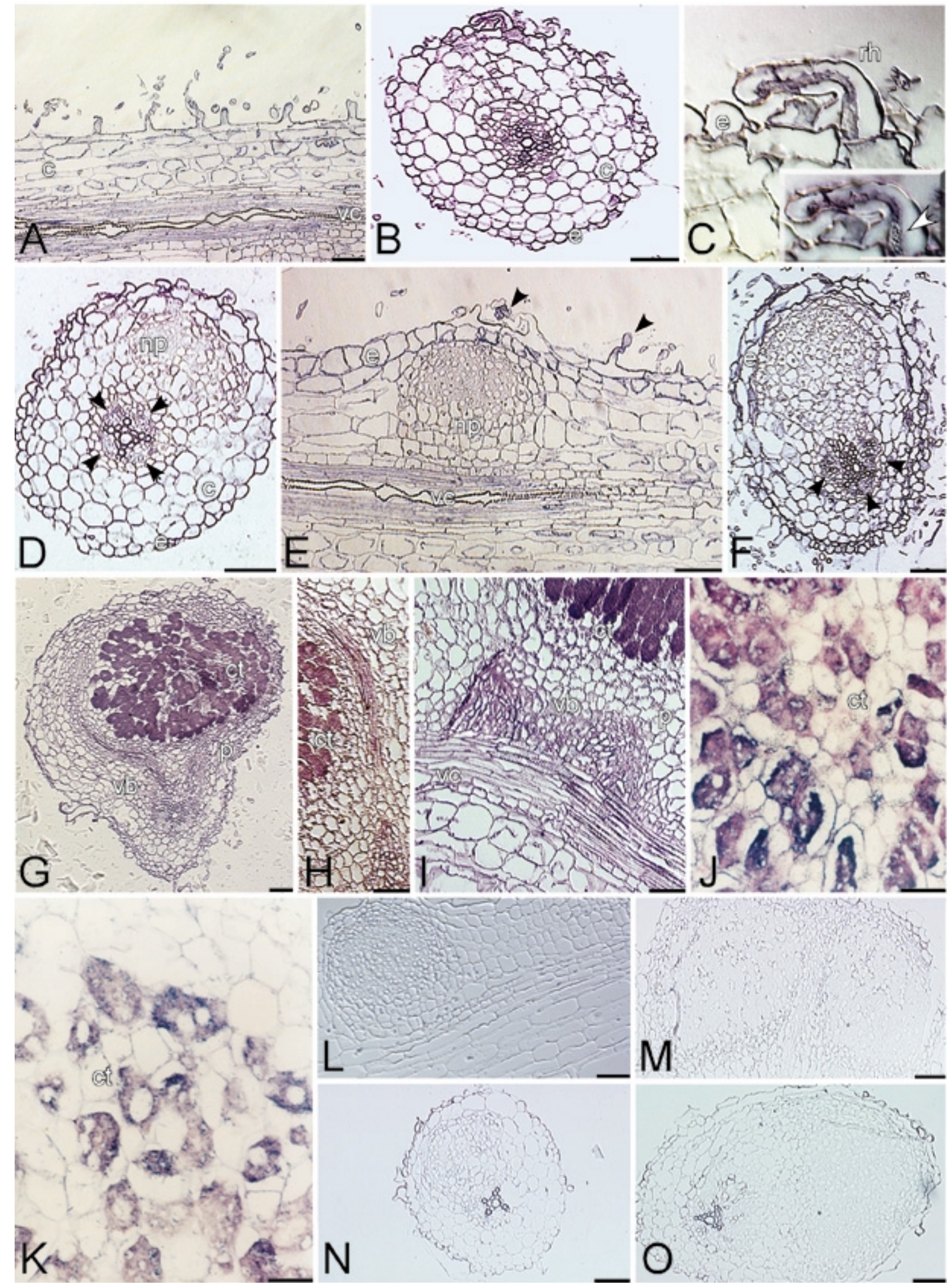

Fig. 6. Immunohistochemical localization of selenium-binding protein (SBP) protein during Lotus japonicus nodule development. Sections of A, the root responsive zone; $\mathbf{B}$ to $\mathbf{F}$, nodule primordia; and nodules at $\mathbf{G}$ and $\mathbf{H}, 14 ; \mathbf{I}, 18 ; \mathbf{J}, 21$; and $\mathbf{K}, 28$ days postinfection were probed with $\mathbf{A}$ to $\mathbf{K}$, SBP antibodies and $\mathbf{L}$ to $\mathbf{O}$, preantisera. $\mathbf{C}$, A Nomarski phase detail micrograph of $\mathbf{B}$ showing a root hair with signal in the infection thread. The inset in $\mathbf{C}$ is the same micrograph with $\mathbf{B}$ only focused at a different level, thus revealing the bacterial structures pointed out by the white arrowhead. D and F, The arrowheads indicate the signal in the phloem. E, The arrowheads indicate root hairs expressing SBP. Signal is detected as a blue-purple precipitate. A, B, D to I, and $\mathbf{L}$ to $\mathbf{O}, \mathbf{B a r s}=50 \mu \mathrm{m}$. $\mathbf{C}$, J, and K, Bars = $25 \mu \mathrm{m}$. c, Cortex; vc, vascular cylinder; e, epidermis; rh, root hair; np, nodule primordium; vb, vascular bundle; and p, parenchyma. 
might be due to either the high stability of the protein or to the higher sensitivity of the detection method.

Based on our expression studies, we hypothesize that $L j$ SBP may have more than one physiological function in leguminous plants. One function, which is possibly related to nodule initiation and function, is triggered by the microsymbiont and might implicate $L j \mathrm{SBP}$ in processes related to membrane synthesis during infection thread and peribacteroid membrane formation. Additionally, it may be involved in nonsymbiotic processes, since it is constitutively expressed in the phloem of the roots and in seedpods, siliques, and embryos. This, in turn, can be correlated with the predicted function as a redox-controlling factor, since such proteins, e.g., the type h thioredoxin RPP13-1 of rice, are localized in the phloem sap (Ishiwatari et al. 1998), and as such, it may regenerate proteins inactivated by oxidative stress or even act as a signal molecule translocated via the phloem stream.

\section{MATERIALS AND METHODS}

\section{Plant material and growth conditions.}

L. japonicus (Gifu B-129) seeds were kindly provided by J. Stougaard (University of Aarhus, Aarhus, Denmark). The plants were gown in a controlled environment with a 16-h-day/ 6-h-night cycle, a $22^{\circ} \mathrm{C}$-day $/ 18^{\circ} \mathrm{C}$-night temperature, and a relative humidity of $70 \%$ (Handberg and Stougaard 1992). Before germination, the seeds were scarified by treatment with $\mathrm{H}_{2} \mathrm{SO}_{4}$ for $5 \mathrm{~min}$ and sterilized for $20 \mathrm{~min}$ in a solution containing $2 \% \mathrm{NaOCl}-0.02 \%$ Tween 20 . Seeds were pregerminated at $18^{\circ} \mathrm{C}$ in the dark for $72 \mathrm{~h}$, and the small plants were grown in Hoagland nutrient solution. Seedlings that were $72 \mathrm{~h}$ old were inoculated with 0.1 optical-density-at-600-nm suspension culture of Mesorhizobium loti (strain E1R.pMP2112), and the plants were grown in nitrogen-free $B \& D$ nutrient solution (Broughton and Dilworth 1971). A. thaliana (ecotype Columbia) plants were grown in soil, in a controlled environment with a 16-h-day/8-h-night cycle at $22^{\circ} \mathrm{C}$, until siliques at various developmental stages were ready for harvesting.

\section{Isolation of cDNA and genomic clones.}

The cDNA clone pGmNOD9, containing a 600-bp insert, was kindly provide by $\mathrm{T}$. Bisseling (Agricultural University of Wageningen, Wageningen, The Netherlands). This clone was the result of the differential screening of a cDNA library constructed in pBR322 from polyA ${ }^{+}$RNA of 10-day-old nodules, with ${ }^{32} \mathrm{P}$-dCTP-labeled poly $\mathrm{A}^{+} \mathrm{RNA}$ of 5-day-old uninfected roots and 10-day-old nodules (Gloudemans 1988).

For the isolation of $L$. japonicus cDNA clones homologous to the GmNOD9 cDNA clone, two $\lambda$ ZAPII L. japonicus cDNA libraries from 9- and 21-day-old nodules (kindly provided by $\mathrm{J}$. Stougaard, University of Aarhus, Denmark) were screened by plaque hybridization using a ${ }^{32} \mathrm{P}$-dCTP-labeled insert of GmNOD9 cDNA clone as a probe. Hybridization was performed under low stringency conditions at $35^{\circ} \mathrm{C}$ in the presence of $25 \%$ formamide. Plaque purification and in vivo excision of pBlueScriptKS ${ }^{+}$plasmids from $\lambda$ ZAPII cDNA library were performed according to the protocols (Stratagene, La Jolla, CA, U.S.A.).

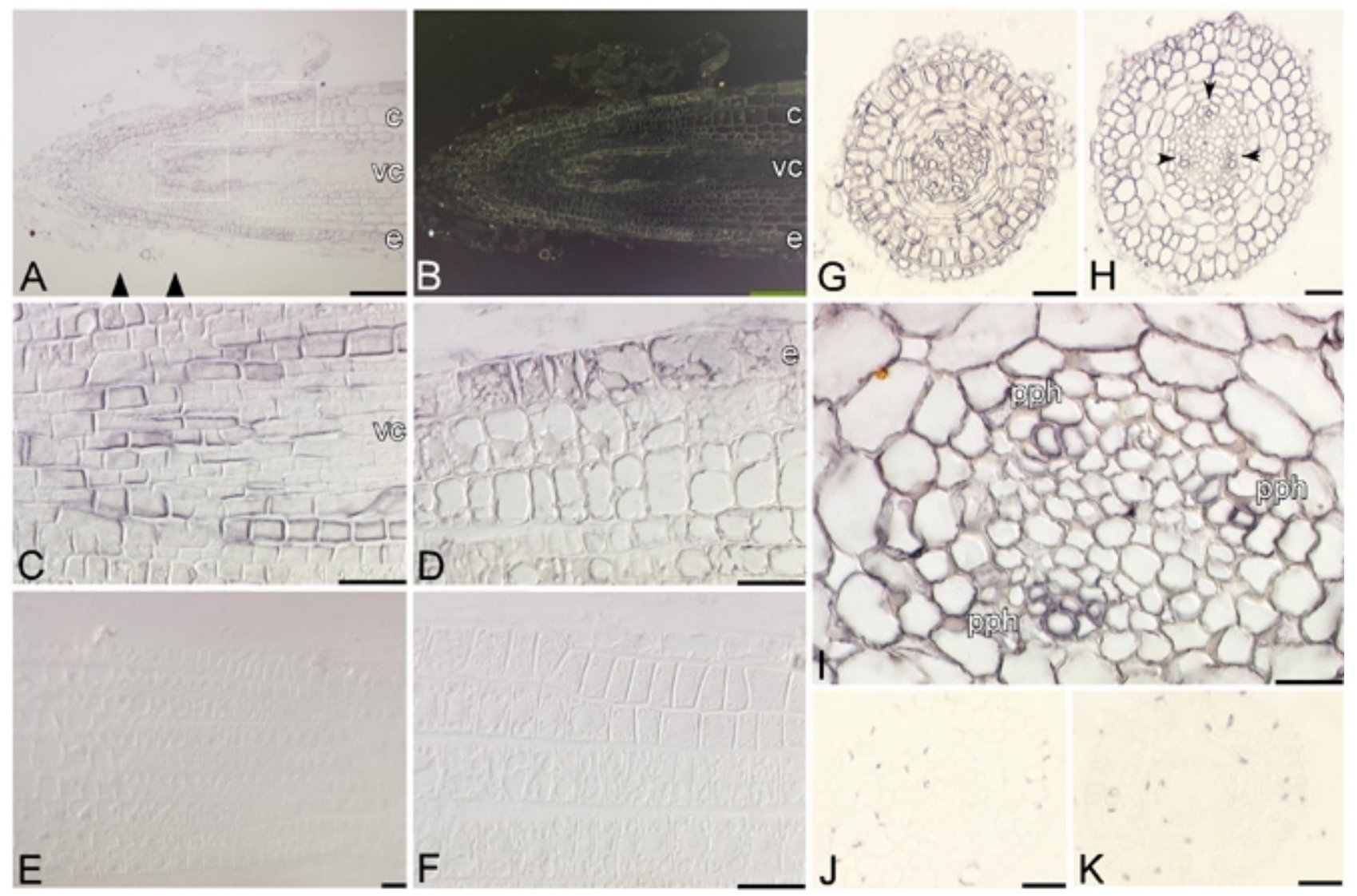

Fig. 7. Immunohistochemical localization of selenium-binding protein (SBP) protein in Lotus japonicus root tips. A to F, Longitudinal and $\mathbf{G}$ to K, transverse sections of $L$. japonicus root tips probed with $\mathbf{E}$ and $\mathbf{F}$, SBP antibodies and $\mathbf{J}$ and $\mathbf{K}$, preantisera. A, The arrowheads indicate the approximate corresponding level of the transverse sections shown in $\mathbf{G}$ and $\mathbf{H}$, respectively. $\mathbf{H}$, Arrowheads indicate the protophloem. I, A magnification of the vascular cylinder in $\mathbf{H}$. C to $\mathbf{F}$ and I, Nomarski phase micrographs. Signal is detected as a blue-purple precipitate, except $\mathbf{B}$, which is the same as $\mathbf{A}$ with inverted colors and the signal is shown in yellow. A and $\mathbf{B}$, Bars $=50 \mu \mathrm{m} ; \mathbf{G}, \mathbf{H}, \mathbf{J}$, and $\mathbf{K}$, Bars $=25 \mu \mathrm{m}$; and $\mathbf{C}$ to $\mathbf{F}$, and $\mathbf{I}$, Bars $=15 \mu \mathrm{m}$. vc, Vascular cylinder; pph, protophloem; e, epidermis; and c, cortex. 
For the isolation of Mssbp cDNA clone, a genomic region was amplified by PCR using the degenerate oligonucleotides D9IIF (5'-ATTATYTGGCKACKGTGGATG-3') and D9IIR (5'-AGYTGAATCATYTGAGGKCC-3') and $M$. sativa genomic DNA as a template. The amplification product was cloned in pBlueScriptKS ${ }^{+}$, and its nucleotide sequence was determined. This clone was designated as $M s g 99$. A $\lambda$ SMART cDNA library was constructed in the Triplex vector (Clontech, Heidelberg, Germany) from polyT-primed cDNA library prepared from 10- to 15-day-old $M$. sativa somatic embryos. This library was screened by plaque hybridization using a radioactively labeled insert of $M s \mathrm{~g} 99$ clone as a probe.

To isolate the gene corresponding to the LjSBP cDNA clone, a $\lambda$ FIXII $L$. japonicus genomic library was screened using a radioactively labeled insert of $L j$ NOD 99 cDNA clone as a probe. Four genomic clones were characterized by physical mapping using Southern hybridization with $\mathrm{LjSBP}$ cDNA as a probe; the DNA fragments carrying the gene were subcloned and sequenced.

\section{Determination of $L j s b p$ gene transcript levels using RT-PCR assay.}

Total RNA was isolated from plant tissues according to Brusslan and Tobin (1992). RNA quality and concentrations were determined spectrophotometrically and by agarose gel electrophoresis. Prior to RT-PCR, all the RNA samples were treated with DNase I (Promega, Madison, WI, U.S.A.) at $37^{\circ} \mathrm{C}$ for $10 \mathrm{~min}$ for the elimination of contaminating genomic DNA. For the reverse transcription and amplification of the Ljsbp gene transcripts, the TitanTM One Tube RT-PCR System (Boehringer Mannheim, Mannheim, Germany) was used. Two primers were used for the reaction designated as RTLjSBP-F (5'-GAGCCATGAGCTTGCAATAC-3') and RTLjSBP-R (5'CAGTTGAATCATCTGAGGG-3'). These primers were designed to hybridize at exon-intron junctions so they would not result in an amplification product from residual genomic DNA. DNase I-treated total RNA (100 ng) was used for each reaction, and the different RNA preparations were normalized by parallel amplification of the constitutively expressed gene LjUbiquitin using $L j \mathrm{UBQ}-\mathrm{F}$ (5'-ATGCAGATCTTTGTGAAAGAC- $\left.3^{\prime}\right)$ and $L j$ UBQ-R (5'-ACCACCACGGAAGACGGAG$\left.3^{\prime}\right)$. In our experimental conditions, a exponential increase of the $L j$ SBP RT-PCR products was still observed after 20 cycles $\left(94^{\circ} \mathrm{C}\right.$ for $1 \mathrm{~min}, 52^{\circ} \mathrm{C}$ for $1 \mathrm{~min}$, and $68^{\circ} \mathrm{C}$ for $1 \mathrm{~min}$ ), so we performed all the reactions under these conditions in order to obtain semiquantitative results. The RT-PCR products were analyzed by agarose electrophoresis, blotted, and hybridized using $L j$ SBP cDNA clone as a probe.

\section{In situ hybridization.}

L. japonicus root nodules and seedpods and A. thaliana siliques harvested at the developmental stages of interest were fixed and embedded in paraffin as previously described (Papadopoulou et al. 1996). Sections (8 to $10 \mu \mathrm{m}$ ) were hybridized with digoxigenin-labeled RNA probes for $16 \mathrm{~h}$ and hybridization signal was visualized using antidigoxigenin conjugated with alkaline phosphatase. Antisense and sense RNA probes labeled with digoxigenin-11-rUTP (Boehringer Mannheim) were transcribed from the $L j S B P$ cDNA clone using T3 and $\mathrm{T} 7$ promoters of pBlueScriptII $\mathrm{KS}^{+}$. Images were processed and prepared for presentation with Photoshop 5.5 (Adobe Systems Inc., San Jose, CA, U.S.A.).

\section{Expression of $L j S B P$ in $E$. coli, purification of the recombinant protein, and rabbit immunization.}

A 1.2-kb Pst I-HindII 3' fragment of the LjSBP cDNA clone was inserted into the pQE-30 expression vector (Qiagen, Hol- den, Germany), and the recombinant plasmid was used to transformed $E$. coli cells strain M15 (Qiagen). The 1.2-kb fragment encodes the first $349 \mathrm{~N}$-terminus amino acids of the SBP polypeptide.

Expression of the recombinant protein was induced with the addition of $2 \mathrm{mM}$ isopropyl- $\beta$-D-thiogalactopyranoside and incubation at $37^{\circ} \mathrm{C}$ for 5 h. E. coli cells expressing the recombinant protein were harvested by centrifugation, and total protein was extracted with extraction buffer $(8 \mathrm{M}$ urea, $0.1 \mathrm{M} \mathrm{Na}$ phosphate, and $0.01 \mathrm{M}$ Tris- $\mathrm{HCl}, \mathrm{pH} 8.0$ ). The recombinant protein carrying the 6 xhis-tag was purified by chromatography through a Ni-NTA matrix (Qiagen) according to standard protocol provided by the manufacturer. The purified recombinant protein was used to immunize rabbits.

\section{Western blot analysis.}

Total nodule proteins were separated into two fractions representing cytosolic and bacteroid proteins (Katinakis et al. 1988). Samples of protein were analyzed by sodium dodecyl sulfate-polyacrylamide gel electrophoresis. After electrophoresis, proteins were electrophoretically transferred to Hybond-C extra nylon membrane (Amersham, Athens, Greece). Antisera against $L j S B P$ recombinant protein (dilution 1:1,500), after absorption in E. coli material, were used to probe the protein blots. The bound antibodies were visualized with the ProtoBlot Western Blot AP System (Promega). Total E. coli extracts were used as a control.

\section{Immunohistolocalization.}

Sections from L. japonicus roots and root nodules were prepared from tissue embedded in butyl/methyl methacrylate according to Ruzin (1999). Sections were blocked for $1 \mathrm{~h}$ in Trisbuffered saline Tween (TBST) buffer containing 3\% bovine serum albumin (BSA) and incubated with the antisera (dilution $1: 1,500$ ) raised against the $L j \mathrm{SBP}$ recombinant protein. The unbound polyclonal antibodies were washed out with TBST buffer. Alkaline phosphatase-conjugated anti-rabbit immunoglobulin $\mathrm{G}$ (Promega) (dilution 1:500 in Tris-buffered saline [TBS] containing $1 \%$ BSA, and $0.05 \%$ Tween 20 ) was used as a second antibody. The signal detection was performed in the alkaline phosphatase substrate, 5-bromo-4-chloro-3-indolylphosphate toluidinium/nitroblue tetrazolium. No signal over background was observed using preimmune serum as a control. Images were processed and prepared for presentation with Photoshop 5.5 (Adobe Systems Inc.).

\section{ACKNOWLEDGMENTS}

This research was supported by the EU grants FMRX-CT96-00390, FMRX-CT98-00243, and HPRN-CT-2000-00086. A. Agalou was supported from the State Scholarships Foundation of Greece (IKY).

\section{LITERATURE CITED}

Bansal, M. P., Mukhopadhyay, T., Scott, J., Cook, R. G., Mukhopadhyay, R., and Medina, D. 1990. DNA sequencing of a mouse liver protein that binds selenium: Implications for selenium's mechanism of action in cancer prevention. Carcinogenesis 11:2071-2073.

Bevan, M., Bancroft, I., Bent, E., et al. 1998. Analysis of 1.9 Mb of contiguous sequences from chromosome 4 of Arabidopsis thaliana. Nature 39:485-488.

Brewin, N., Wood, E. A., Bradley, D. J., Harding, S. C., Sindhu, S. S., Perotto, S., Kannenberg, E. L., and Van den Bosch, K. A. 1988. The use of monoclonal antibodies to study plant-microbe interactions in pea nodule. Pages 517-525 in: Nitrogen Fixation: Hundred Years After. H. Rothe, F. J. de Bruijn, and W. E. Newton, eds. Gustav Fischer Verlag, Stuttgart, Germany.

Broughton, W. J., and Dilworth, M. 1971. Control of leghemoglobin synthesis in snake beans. Biochem. J. 125:1075-1080.

Brusslan, J. A., and Tobin, E. M. 1992. Light-independent development 
regulation of $c a b$ gene expression in Arabidopsis thaliana seedlings. Proc. Natl. Acad. Sci. U.S.A. 89:7791-7795.

Charon, C., Carolina, S., Crespi, M., and Kondorosi, A. 1999. Alteration of enod40 expression modifies Medicago trunculata root nodule development induced by Rhizobium meliloti. Plant Cell 11:1953-1965.

Cho, M.-J., Wong, J. H., Marx, W. C., Jiang, W., Lemaux, P. G., and Buchanan, B. B. 1999. Overexpression of thioredoxin leads to enhanced activity of starch debranching enzyme (pullulanase) in barley grain. Proc. Natl. Acad. Sci. U.S.A. 96:14641-14646.

Cook, D., Dreyer, D., Bonnet, D., Howell, M., Nony, E., and van den Bosh, K. 1995. Transient induction of a peroxidase gene in Medicago trunculata precedes by Rhizobium loti. Plant Cell 7:43-55.

Crespi, M. D., Jurkevitch, E., Poiser, M., D'Aubenton-Carafa, Y., Pertrovics, G., Kondorosi, E., and Kondorosi, A. 1994. Enod40, a gene expressed during nodule organogenesis, codes for a non-translatable RNA involved in plant growth. EMBO (Eur. Mol. Biol. Organ.) J. 13: 5099-5112.

Dean, R. M., Rivers, R. L., Zeidel, M. L., and Roberts, D. M. 1999. Purification and functional reconstruction of soybean nodulin 26. An aquaporin with water and glycerol transport properties. Biochemistry 38 : 347-353.

Doolittle, R. F. 1992. Reconstruction history with amino acids sequences. Protein Sci. 1:191-200.

Fang, Y., and Hirsch, A. M. 1998. Studying early nodulin gene ENOD40 expression and induction by nodulation factor and cytokinin in transgenic alfalfa. Plant Physiol. 116:53-68.

Flemetakis, E., Kavroulakis, N., Quaedvlieg, N. E. M., Spaink, H. S., Dimou, M., Roussis, A., and Katinakis, P. 2000. Lotus japonicus contains two distinct ENOD40 genes that are expressed in symbiotic, nonsymbiotic, and embryonic tissues. Mol. Plant-Microbe Interact. 13: 987-994.

Gallois, P., Makishima, T., Hecht, V., Despras, B., Laudie, N., Yakeharu, N., and Cooke, R. 1997. An Arabidopsis thaliana cDNA complementing a hamster apoptosis suppressor mutant. Plant J. 13:1325-1331.

Gloudemans, T. 1988. Plant gene expression in early-stages of Rhizobium-legume symbiosis. Ph.D. thesis. Agricultural University of Wageningen, Wageningen, The Netherlands

Handberg, K., and Stougaard, J. 1992. Lotus japonicus, an autogamous, diploid legume species for classical and molecular genetics. Plant J. 2:487-496.

Hata, S., Izui, K., and Kouchi, H. 1998. Expression of soybean noduleenhanced phosphoenolpyruvate carboxylase gene that shows striking similarity to another gene for house-keeping isoform. Plant J. 13:267273

Ishiwatari, Y., Fujiwara, T., McFarland, K. C., Nemoto, K., Hayashi, H., Chino, M., and Lucas, W. J. 1998. Rice phloem thioredoxin h has the capacity to mediate its own cell-to-cell transport through plasmodesmata. Planta 205:12-22.

Jamba, L., Nehru, B., and Bansal, M. P. 1997. Redox modulation of selenium binding proteins by cadmium expose in mice. Mol. Cell Biochem. 177:169-175.

Kapranov, P., Jensen, T. J., Poulsen, C., de Bruijn, F., and Szczglowski, K. 1999. A protein phosphatase $2 \mathrm{C}$ gene, $L j N P P 2 C 1$, from Lotus japonicus induced during root nodule development. Proc. Natl. Acad. Sci. U.S.A. 96:1738-1743

Katinakis, P., Klein Lankhorst, R. M., Louwerse, J., van Kammen, A., and van de Bos, R. C. 1988. Bacteroid-encoded proteins are secreted into the peribacteroid space by Rhizobium leguminosarum. Plant Mol. Biol. 11:183-190.

Kavroulakis, N., Flemetakis, E., Aivalakis, G., and Katinakis, P. 2000 Carbon metabolism in developing soybean root nodules: The role of carbonic anhydrase. Mol. Plant-Microbe Interact. 13:14-22.

Kawalleck, P., Schmelzer, E., Hahlbrock, K., and Somssicch, I. E. 1995. The pathogen-responsive genes in parsley encode a tyrosine-rich hydroxyproline glycoprotein ( $\mathrm{hrgp}$ ) and an anionic peroxidase. Mol. Gen. Genet. 247:444-452.

Kijne, J. W. 1992. The Rhizobium infection process. Pages 349-398 in: Biological Nitrogen Fixation. G. Stacey, R. H. Burris, and H. J. Evans, eds. Chapman and Hall, New York.

Kouchi, H., and Hata, S. 1995. GmN56, a novel nodule-specific cDNA from soybean root nodules encodes a protein homologous to isopropylmalate synthase and homocitrate synthase. Mol. Plant-Microbe Interact. 8:172-176.

Kouchi, H., Takane, K., So, R. B., Ladha, J. K., and Reddy, P. M. 1999.
Rice ENOD40: Isolation expression analysis in rice and transgenic soybean root nodules Plant J. 18:121-129.

Lanfear, J., Fleming, J., Walker, M., and Harrison, P. 1993. Different patterns of regulation of the genes encoding the closely related $56 \mathrm{kDa}$ selenium- and acetaminophen proteins in normal tissues and during carcinogenesis. Carcinogenesis 14:335-340.

Liu, Y.-S., and Stadtman, C. T. 1997. Heparin-binding properties of selenium-containing thioredoxin reductase from HeLa cells and human lung adenocarcinoma cells. Proc. Natl. Acad. Sci. U.S.A. 94:61386141.

Marchfelder, A., Binder, S., and Brennicke, A. 1997. A nodulin-35 homologue is encoded in Arabidopsis genome. Trends Plant Sci. 2:167-168.

Matvienko, M., van de Sande, K., Pawlowski, K., van Kammen, A., Franssen, H., and Bisseling, T. 1996. Nicotiana tabacum SR1 contains two ENOD40 homologs. Pages 387-391 in: Biology of Plant-Microbe Interactions. G. Stacey, B. Mullin, and P. M. Gresshoff, eds. International Society for Molecular Plant-Microbe Interactions, St. Paul, MN, U.S.A.

Meyer, Y., Verdoucq, L., and Vignol, F. 1999. Plant thioredoxins and gluredoxins: Identity and its putative roles. Trends Plant Sci. 4:388394.

Mylona, P., Pawlowski, K., and Bisseling, T. 1995. Symbiotic nitrogen fixation. Plant Cell 5:869-885.

Papadopoulou, K., Roussis, A., and Katinakis, P. 1996. Phaseolus ENOD40 is involved in symbiotic and non-symbiotic organogenesis processes: Expression during nodule and lateral root development. Plant Mol. Biol. 30:403-417.

Porat, A., Sagiv, Y., and Elazar, Z. 2000. A 56-kDa selenium-binding protein participates in intra-Golgi protein transport. J. Biol. Chem. 275: 14457-14465.

Radice, P., Pensotti, V., Jones, C., Perry, H., Pierotti, M. A., and Tunnacliffe, A. 1995. The human arcain gene, ARC1, has highly conserved homologs in rice and Drosophila. Genomics 26:101-106.

Reddy, P. M., Kouchi, H., and Ladha, J. K. 1998. Isolation, analysis and expression of homologues of the soybean early nodulin gene GmENOD93 (Gm93) from rice. Biochim. Biophys. Acta 1433:386-392.

Robertson, J. G., Lyttleton, P., Bullivant, S., and Grayston, G. F. 1978. Membranes in lupin root nodules. I. The role of Golgi bodies in the biogenesis of infection threads and peribacteroid membranes. J. Cell Sci. 30:129-149.

Rodriguez, C. M., Freire, M. A., Camillieri, C., and Robaglia, C. 1998. The Arabidopsis thaliana cDNAs coding for elF4E and elF(iso)4E are not functionally equivalent for yeast complementation and are differentially expressed during plant development. Plant J. 13:465-473.

Roth, L. E., and Stacey, G. 1989a. Cytoplasmic membrane systems involved in bacterium release into soybean nodule cells as studied with two Bradyrhizobium japonicum mutant strains. Eur. J. Cell Biol. 49: 24-32.

Roth, L. E., and Stacey, G. 1989b. Bacterium release into host cells of nitrogen-fixing soybean nodules: The symbiosome membrane comes from three sources. Eur. J. Cell Biol. 49:13-23.

Ruzin, E. S. 1999. Plant Microtechnique and Microscopy. Oxford University Press, New York.

Sandal, N. N., and Marcker, K. A. 1988. Soybean nodulin 26 is homologous to the major intrinsic protein of bovine lens fiber membrane. $\mathrm{Nu}-$ cleic Acids Res. 16:9347.

Schauser, L., Roussis, A., Stiller, J., and Stougaard, J. 1999. A plant regulator controlling development of symbiotic root nodules. Nature 402: 191-196.

Scheres, B., van Engelen, F., van der Knaup, E., van de Wiel, C., van Kammen, A., and Bisseling, T. 1990. Sequential induction of nodulin gene expression in developing pea nodule. Plant Cell 2:687-700.

Shiels, A., Kent, N. A., McHale, M., and Bangham, J. A. 1988. Homology of MIP26 and Nod26. Nucleic Acids Res. 16:9346.

Takane, K.-i., Tajima, S., and Kouchi, H. 1997. Two distinct uricase II (nodulin 35) genes are differentially expressed in soybean plants. Mol. Plant-Microbe Interact. 10:735-741.

Trevaskis, B., Watt, R. A., Andersson, C. R., Liewellyn, D. J., Hagrove, M. S., Olson, J. S., Dennis, E. S., and Peacock, W. J. 1997. Two hemoglobins in Arabidopsis thaliana the evolutionary origins of hemoglobin. Proc. Natl. Acad. Sci. U.S.A. 94:12230-12234.

Yang, M., and Sytkowski, A. J. 1998. Differential expression and androgen regulation of the human selenium-binding protein gene $h S P 56$ in prostate cancer cells. Cancer Res. 58:3150-3153. 